Management, Procurement and Law Volume 170 Issue MP1

Impact of knowledge management on construction projects

Suresh, Olayinka, Chinyio and Renukappa
Proceedings of the Institution of Civil Engineers

Management, Procurement and Law 170 February 2017 Issue MP1

Pages 27-43 http://dx.doi.org/10.1680/jmapl.15.00057

Paper 1500057

Received 07/12/2015 Accepted 26/10/2016

Published online 05/12/2016

Keywords: knowledge management/project management/quality control

ICE Publishing: All rights reserved i

\title{
Impact of knowledge management on construction projects
}

Subashini Suresh BEng, MEng, PhD, FHEA

Reader, Faculty of Science and Engineering, University of Wolverhampton, Wolverhampton, UK (corresponding author: s.subashini@wlv.ac.uk)

Raymond Olayinka BSc (Hons), MBA, PhD

Knowledge Management Specialist, Mott MacDonald, London, UK
Ezekiel Chinyio BSc (Hons), MSc, PhD

Senior Lecturer, Faculty of Science and Engineering, University of Wolverhampton, Wolverhampton, UK

Suresh Renukappa BEng, MEng, PhD, PGCAPHE, MInLM, FHEA MBAM

Senior Lecturer, Faculty of Science and Engineering, University of Wolverhampton, Wolverhampton, UK

The implementation of knowledge management strategies on construction projects can accrue benefits such as improved performance and continuous improvement. However, many projects are still not utilising knowledge management fully and are thus plagued with inefficiencies, repetition of mistakes and lack of lessons learnt. Poor skills, design changes, errors and omissions contribute to the internal failure cost element of the overall cost of poor quality on construction projects. This study aimed to investigate the extent of the impact that knowledge management has in reducing the cost of poor quality and used a mixed-methods approach. In-depth interviews were conducted with 25 construction industry experts on knowledge management across the UK, followed up by a questionnaire survey of 114 respondents. The data obtained were analysed using thematic analysis and descriptive statistics. It was found that knowledge management had a positive impact in reducing the cost of poor quality, in particular in the area of knowledge transfer through apprenticeships and mentoring. This implies the importance of managing the tacit knowledge of employees through 'socialisation' initiatives. This study contributes to the existing body of knowledge by providing a knowledge management framework for reducing the cost of poor quality on construction projects.

\section{Introduction}

Knowledge management (KM) is invaluable to construction management due to its contribution towards harnessing and integrating knowledge across personal, organisational, project and industry boundaries. KM implementation strategies can reap benefits such as improved project performance and continuous improvement, yet many projects are plagued with inefficiencies, repetition of mistakes and lack of lessons learnt, thereby contributing to additional project costs (Al-Ghassani et al., 2004; Carrillo et al., 2013; Chatterjee, 2013; Egbu, 2005; Ren et al., 2013; Suresh et al., 2008). A major area of focus is on the cost attached to the unnecessary effort of redoing processes or activities that were incorrectly implemented the first time, often referred to as the cost of poor quality (COPQ). This constitutes the cost of errors and omissions, cost of design changes, cost of poor skills and the consequential costs associated with client dissatisfaction (Feigenbaum, 1986; Garstenauer et al., 2014; Josephson and Hammarlund, 1999; Juran and Godfrey, 1998; Love and Edwards, 2005; Rosenfeld, 2009).

COPQ has been found to be prevalent on many projects, regardless of type or size. Burati et al. (1992) found quality deviations in nine engineering projects to be an average of $12.4 \%$ of the contract value. Abdul-Rahman (1995) found the nonconformance costs to be $5 \%$ of contract value on a highway project. Nylén (1996) found quality failures to be $10 \%$ of the contract value on a railway project. Love and $\mathrm{Li}$ (2000) found rework costs in residential and industrial buildings to be $3 \cdot 15$ and $2 \cdot 4 \%$ of the contract value, respectively. Researchers have attempted to find the mean value of COPQ. Love (2002) found the mean direct and indirect rework costs on 161 construction projects to be $6 \cdot 4$ and $5 \cdot 6 \%$ of the original contract value, respectively. Hwang (2009) obtained data from 359 construction projects and found the direct rework costs alone to be $5 \%$ of the total construction costs. Love et al. (2010) found the mean rework costs to be $10 \%$ of the contract value in civil infrastructure projects.

COPQ is endemic and is a major contributory factor to client dissatisfaction, reduced profitability of the supply chain and reduced reputation of the construction industry as a whole. There is therefore a critical need to formulate strategies for reducing COPQ on projects. While COPQ may be regarded as a quality management problem, in which case initiatives such as total quality management, Six Sigma and Lean principles are applicable for its implementation, this study takes a novel approach to exploring the impact of KM on COPQ. Previous KM studies have focused on harnessing knowledge at the personal and organisational levels but not at the project and industry levels. These past studies have focused on constituent aspects such as rework, delays and wastage, but none was found to have adopted 
a holistic approach by integrating all these aspects. Furthermore, no research was found to date that has examined the extent of the impact which KM has on COPQ.

The aim of the study, therefore, was to investigate the extent of the impact which KM has in reducing COPQ on construction projects. The objectives were fourfold: $(a)$ to examine the existing body of work in the areas of KM and COPQ in order to generate key research questions; $(b)$ to conduct a field study with industry experts based on the research questions generated; $(c)$ to discuss the findings; and $(d)$ to draw conclusions and indicate directions for further studies. The next sections present the literature review and methodology adopted. Thereafter, the findings and conclusions are discussed

\section{Literature review}

$\mathrm{KM}$ and COPQ are wide subject areas with various conceptualisations and applications. The study examined the existing body of work in these areas and adopted relevant concepts.

\subsection{KM conceptualisation and application}

Despite the vast body of research on KM, there appears to be no universal definition of the term, just as there is no consensus as to what constitutes knowledge in the first place. From the way knowledge is described by different authors, it is obvious that it is conceptualised in divergent ways (Hislop, 2005). The competing conceptualisations are based on fundamentally different epistemologies - that is, the philosophy addressing the nature of knowledge, which is concerned with questions such as the following: is knowledge objective and measureable? Can knowledge be acquired or is it experienced? What is regarded as valid knowledge and why?

The various definitions of knowledge can be summarised and classified into (a) classical-era definitions of knowledge as being a justified true belief (e.g. Plato, Aristotle) and (b) contemporaryera definitions of knowledge as being a fluid mix of framed experiences, values, contextual information and expert insight that provides a framework for evaluating and incorporating new experiences and information (e.g. Davenport and Prusak, 1998; Drucker, 1999). The contemporary definitions are more relevant to construction management, as they focus on the pragmatics of using knowledge and on the notion of knowledge as a practical tool for framing experiences, sharing insights and assisting with practical tasks. KM therefore entails understanding the uses of knowledge in order to deal effectively with the practical tasks that involve knowledge-based activities.

A dominant aspect of $\mathrm{KM}$ is that of knowledge conversion, in particular where new knowledge is created through the interfaces between tacit and explicit knowledge. While explicit knowledge is often formal and systematic and can be shared easily, tacit knowledge is personal and hard to formalise, and can be difficult to capture or communicate to others (Nonaka and Takeuchi, 1995; Nonaka and Toyama, 2005; Polanyi, 1966). Knowledge conversion is made up of four interfaces known by the acronym 'SECI': socialisation (i.e. the conversion of tacit knowledge to tacit knowledge), externalisation (tacit to explicit), combination (explicit to explicit) and internalisation (explicit to tacit). SECI is applicable to the construction supply chain in facilitating knowledge interactions across personal, organisational, project and industry boundaries (see Figure 1). The operational definition of KM in the context of this study therefore is linked to these interactions; thus, $\mathrm{KM}$ entails the process of harnessing and integrating knowledge across personal, organisational, project and industry boundaries in order to make the most effective use of knowledge.

The process of harnessing and integrating knowledge constitutes certain subprocesses which have been identified and defined in different ways by different authors. As a result, there is a lack of common terminology used in describing these subprocesses. It is therefore important to examine these subprocesses in order to clarify the overlaps in the use of terminology. A sample is drawn from the subprocesses presented by authors, in particular in the past two decades when KM gained popularity in the industry and academia.

In total, 41 terminologies were identified from various definitions and reorganised into eight distinct $\mathrm{KM}$ subprocesses, namely, 'identify', 'capture', 'codify', 'store', 'access', 'exploit', 'create' and 'assess' (see Table 1).

(a) 'Identify' involves recognising sources and types of knowledge for the benefit of an organisation, particularly in supporting business processes (Liebowitz, 1999; Lytras et al., 2002). Other terms used by authors to describe the same process include 'source', 'select', 'explore' and 'discover'.

(b) 'Capture' involves the act of recording identified knowledge in organisational files and knowledge bases. Collison and Parcell (2001) described knowledge capture as a means of capturing know-how in such a way that it can be reused. One of the first steps in capturing knowledge is to identify the sources of critical knowledge that might be at risk in an organisation - for example, an employee leaving due to downsizing or retirements. Other terms used for 'capture' by authors include 'collect', 'acquire', 'absorb' and 'abstract'.

(c) 'Codify' is the acquisition of knowledge from its source in the most efficient way possible in order to permit knowledge reusability within the organisation (Lytras et al., 2002). The purpose of knowledge codification is to capture experiences and make them available in the present either to those who were part of the original experience itself or to an entirely new set of employees altogether (Holthouse, 1999). Other terms used by authors for 'codify' include 'classify', 'modify,' 'organise', 'transform', 'compile', 'coordinate', 'structure', 'develop', 'focus' and 'filter'.

(d) 'Store' involves retaining knowledge in an organisational memory unit or knowledge base (Robinson et al., 2001). Other terms used for 'store' include 'maintain', 'archive' and 'secure'.

(e) 'Access' refers to the ease of locating and retrieving of the right knowledge by the right people at the right time 


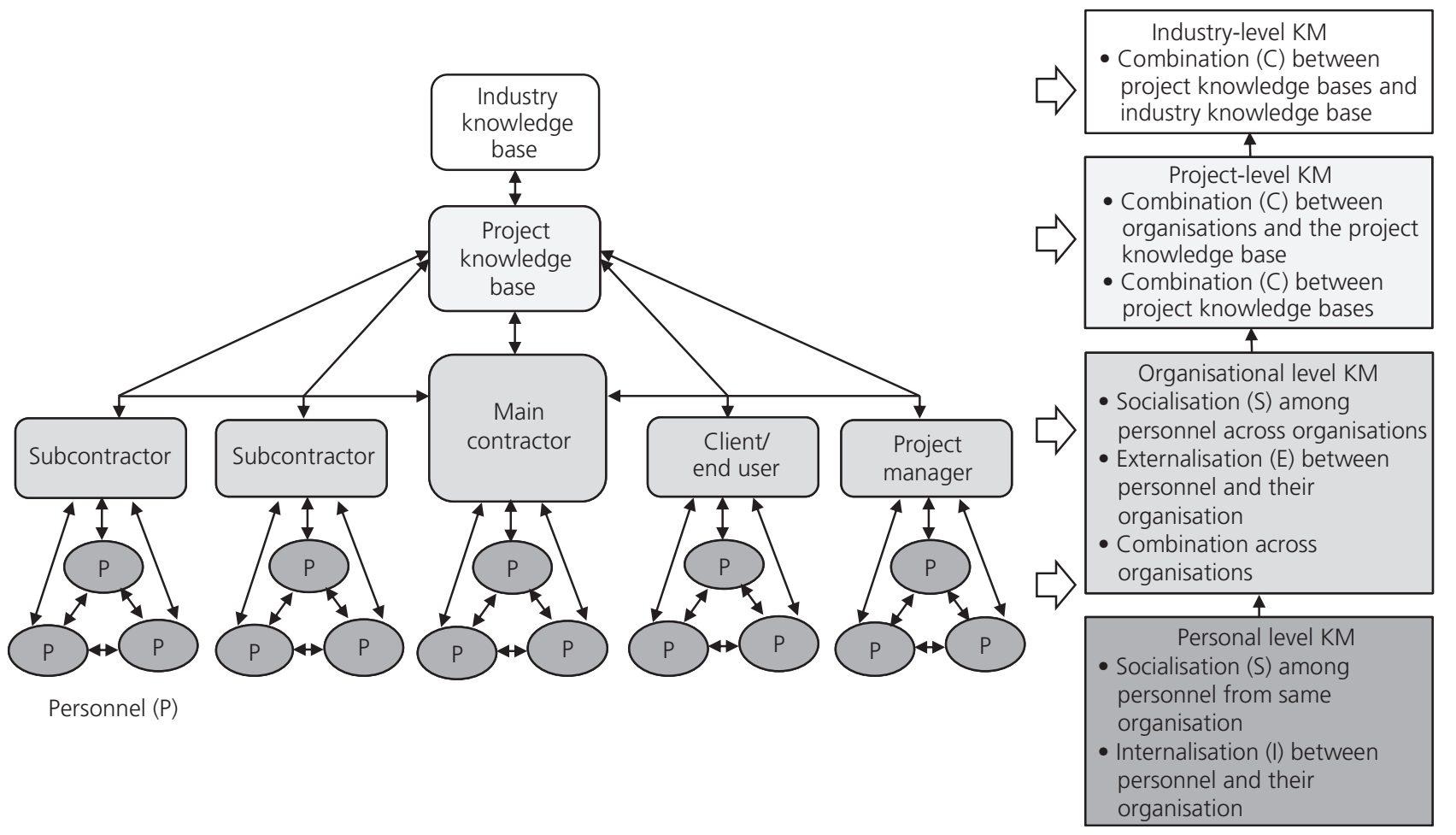

Figure 1. Application of SECI to the construction supply chain

(O'Dell and Grayson, 1998). 'Access' is also termed 'retrieve' by some authors.

$(f)$ 'Exploit' involves the optimal use of knowledge for organisational and individual benefits. It includes activities that facilitate the knowledge conversion process (Nonaka and Takeuchi, 1995) at the individual, organisational or interorganisational levels. Knowledge exploitation involves several subprocesses which have been identified by authors such as 'disseminate', 'share', 'transfer', 'distribute', 'sell', 'deploy', 'diffuse', 'mobilise', 'learn', 'use', 'reuse', 'apply', 'leverage', 'strategise' and 'utilise'.

(g) 'Create' is the strategic organisational ability to bring into existence or originate new knowledge continuously and repeatedly in a circular process with no ultimate end (Egbu et al., 2001; Storey and Quintas, 2001). Knowledge creation involves the generation and discovery of new knowledge. According to Nonaka and Takeuchi (1995), knowledge creation should be viewed as a process whereby the organisation amplifies the knowledge created by employees and crystallises it as part of the knowledge network of the organisation. Similarly, Tiwana (2002) stated that a successful KM project must begin with knowledge that already exists, deliver initial results and then continue to expand on it. New knowledge is usually created as one of the outcomes of managing existing knowledge. Other authors use the synonym 'generate' to signify knowledge creation.

(h) 'Assess' refers to the measurement and benchmarking of KM outcomes within an organisation. Some authors have used the terms 'validate', 'evaluate' and 'measure' to refer to assessment of knowledge.

These eight subprocesses can be further classified into three main headings (see Figure 2).

(a) Knowledge acquisition is the process of absorbing and storing knowledge, the success of which is often gauged by how well the knowledge can be retrieved later. Subprocesses $(a)-(e)$ (i.e. identify, capture, codify, store, access) fit into knowledge acquisition.

(b) Knowledge exploitation involves the unitisation of knowledge optimally for the benefit and profit of an organisation.

Subprocesses $(f)$ and $(g)$ (e.g. disseminate, share, transfer, create new knowledge) belong to this category.

(c) Knowledge evaluation is a systematic determination of merit by using criteria governed by a set of standards which assists an organisation to ascertain the degree of achievement or value in regard to the aim and objectives of an undertaken project. Subprocess $(h)$ (i.e. validate, evaluate, measure) belongs to this category.

\subsection{COPQ conceptualisation and application}

The COPQ concept stems from quality management, in particular in the manufacturing industry, but it has found expression in other industries, including construction. Defining the term 'quality' itself can be a challenging task since it is often a perceptual, conditional and subjective attribute that may be conceptualised in different 


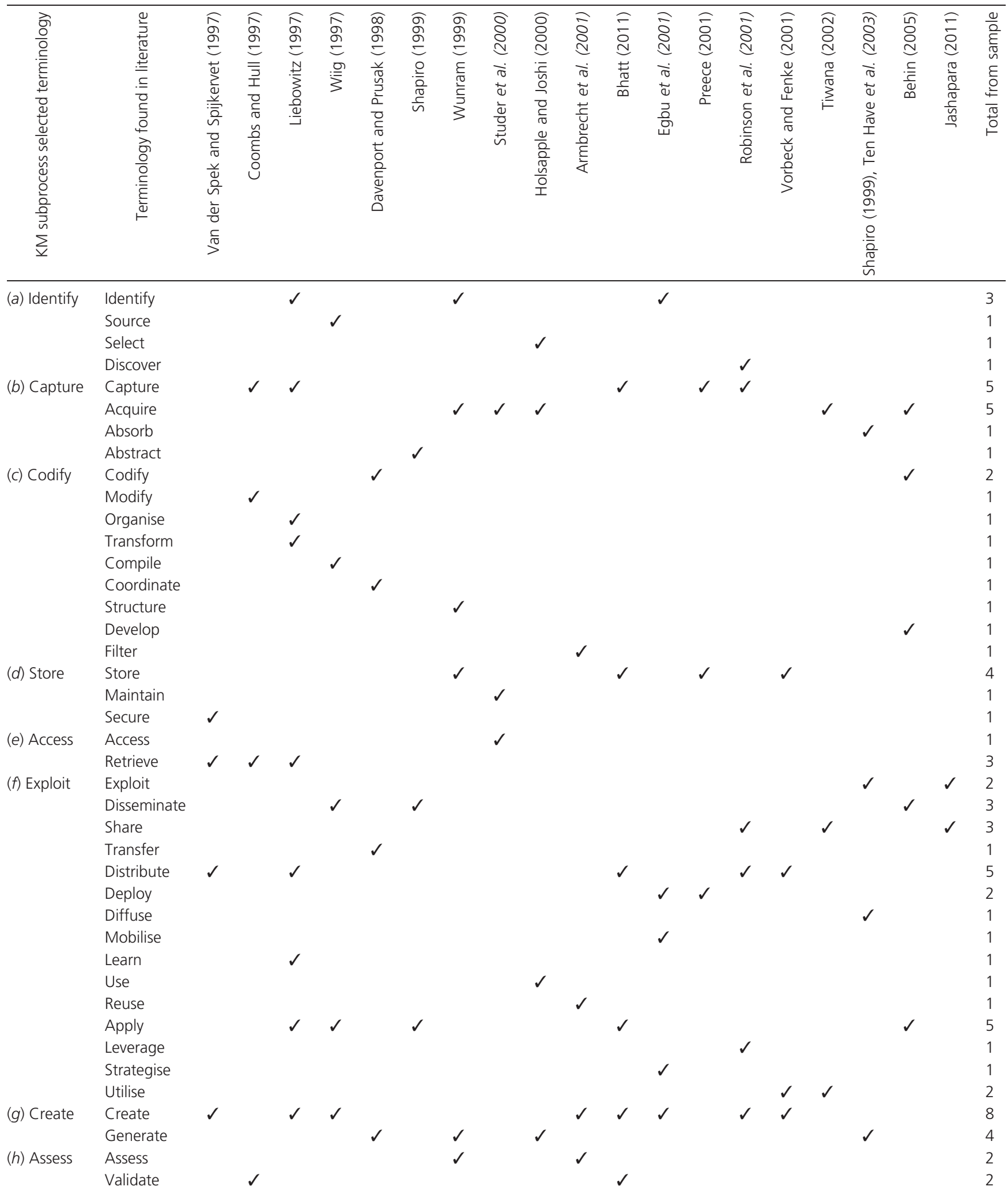

Table 1. KM subprocesses 


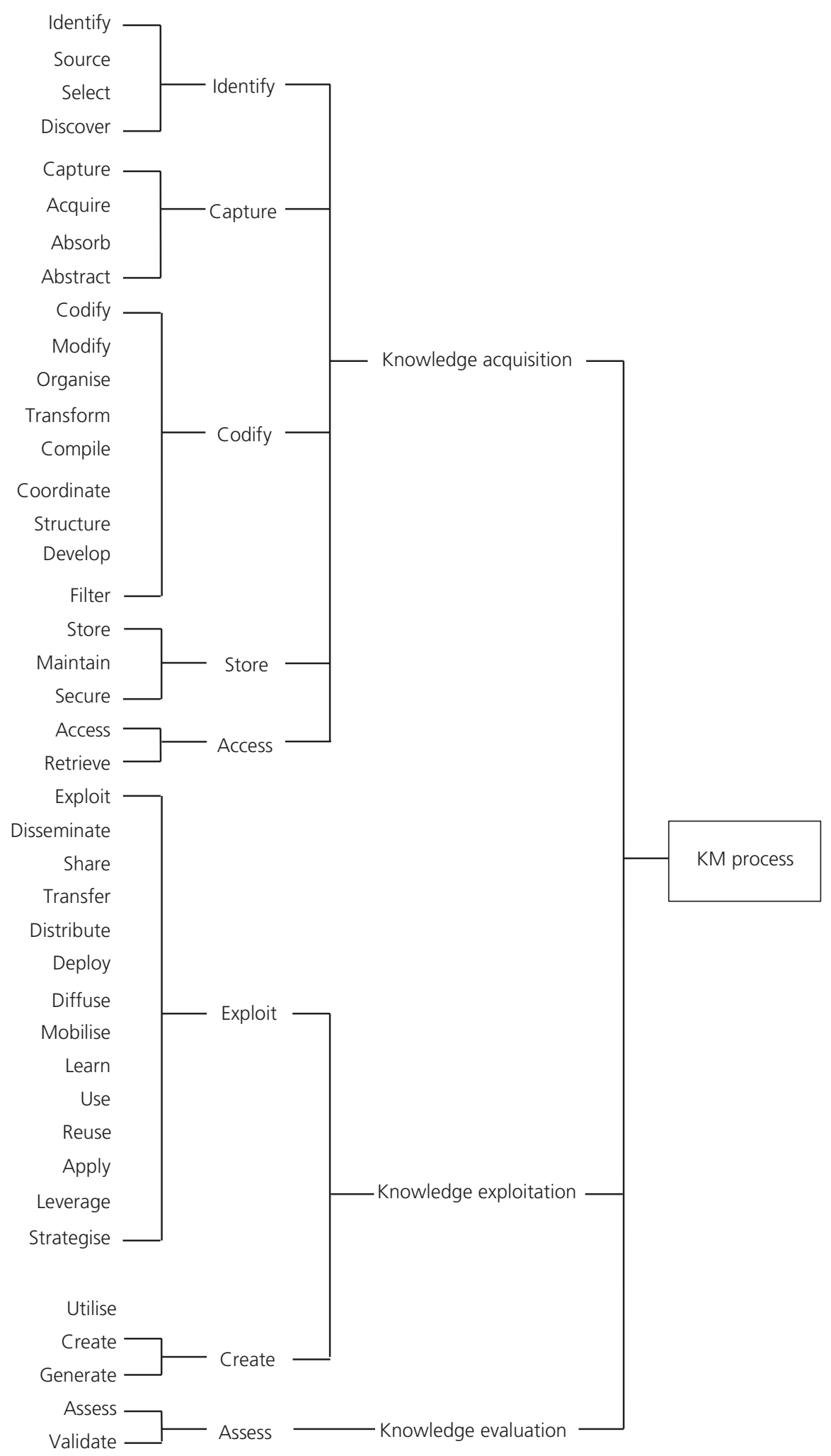

Figure 2. KM subprocess classification based on author definitions 
ways. Quality in the construction management context is based on an agreed set of criteria defined by the project stakeholders, including the client, designers and the main contractor (Olayinka et al., 2011). These criteria may include conformance to requirements, achievement of zero defects, use of efficient processes, achievement of client satisfaction, cost reduction and increased profit (Crosby, 1979; ISO, 2005; Kano et al., 1984; Taguchi, 1993). Deviation from these set criteria therefore would tend towards poor quality; consequently, the unnecessary cost associated with rectifying poor quality is termed 'COPQ'.

A widely used concept in classifying COPQ is the prevention-appraisal-failure cost model elaborated on by Feigenbaum (1986) and Juran and Godfrey (1999). Prevention and appraisal costs are incurred by organisations to ensure that their products or services are delivered right the first time. Failure costs are either internal (i.e. failure to meet explicit requirements or implicit needs of the client/end user before product handover) or external (i.e. failure to meet requirements after handover).

While prevention and appraisal costs are necessary costs referred to as the cost of good quality, failure costs are unnecessary and avoidable; therefore, they are referred to as COPQ, which this study focused on. Three subdivisions of COPQ emerged from various studies, namely, cost of errors and omissions, cost of design changes and cost of poor skills (Burati et al., 1992; Chung, 1999; Feigenbaum, 1986; Hwang, 2009; Love et al., 1999, 2004). Reducing these costs requires a holistic approach to construction management. Figure 3 shows the interrelationships among the constituent elements of COPQ - that is, the consequential costs of rework, delays and wastage and the cost indicators measured in terms of plant, material, labour and time.

\subsection{Incorporating $\mathrm{KM}$ with the $\mathrm{COPQ}$}

The rationale for undertaking this research was driven by the need to reduce COPQ on construction projects. $\mathrm{KM}$ is invaluable to the construction industry, as it is deemed critical for construction organisations to harness and integrate knowledge in order to improve efficiency and increase profitability. The way in which the construction industry is organised means that efficiency in project delivery is currently less than expected, resulting in dissatisfied clients and low profitability for construction organisations. There is an awareness of the need to manage employee-owned tacit knowledge within construction organisations strategically (Anand et al., 2010; Carrillo and Chinowsky, 2006) and the need for knowledge integration across personal, organisational and project boundaries (Ruan et al., 2012).

While attempts have been made by some authors to quantify COPQ, none of them has adopted a holistic approach. Instead, previous studies have focused on the constituent aspects of COPQ, such as quality failures (e.g. Nylén, 1996), non-conformance costs (e.g. Abdul-Rahman, 1995), deviation costs (e.g. Burati et al., 1992; Cnuddle, 1991), direct and indirect rework costs (e.g. Hwang, 2009; Love, 2002) and design and construction related change orders (e.g. Cox, 1999; Love et al., 2010). A more holistic approach would be to integrate all the aspects of errors and omissions, design changes and poor skills, which all contribute to rework, delays and wastage, which are quantifiable in terms of plant, material, labour, time and penalty costs (see Figure 3). None of the existing body of work has examined the impact of $\mathrm{KM}$ on COPQ or presented empirical evidence on the level of this impact. This study therefore set out to explore these areas by incorporating the KM model presented in Figure 1 with the COPQ model presented in Figure 3 in order to investigate the impact of $\mathrm{KM}$ on COPQ in practice. The key questions addressed were as follows. (a) What is the impact of KM on the cost of errors? (b) What is the impact of $\mathrm{KM}$ on the cost of design changes? (c) What is the impact of $\mathrm{KM}$ on the cost of poor skills?

While KM and COPQ may be viewed as two distinct areas in practice, evidence suggests that one impacts upon the other.

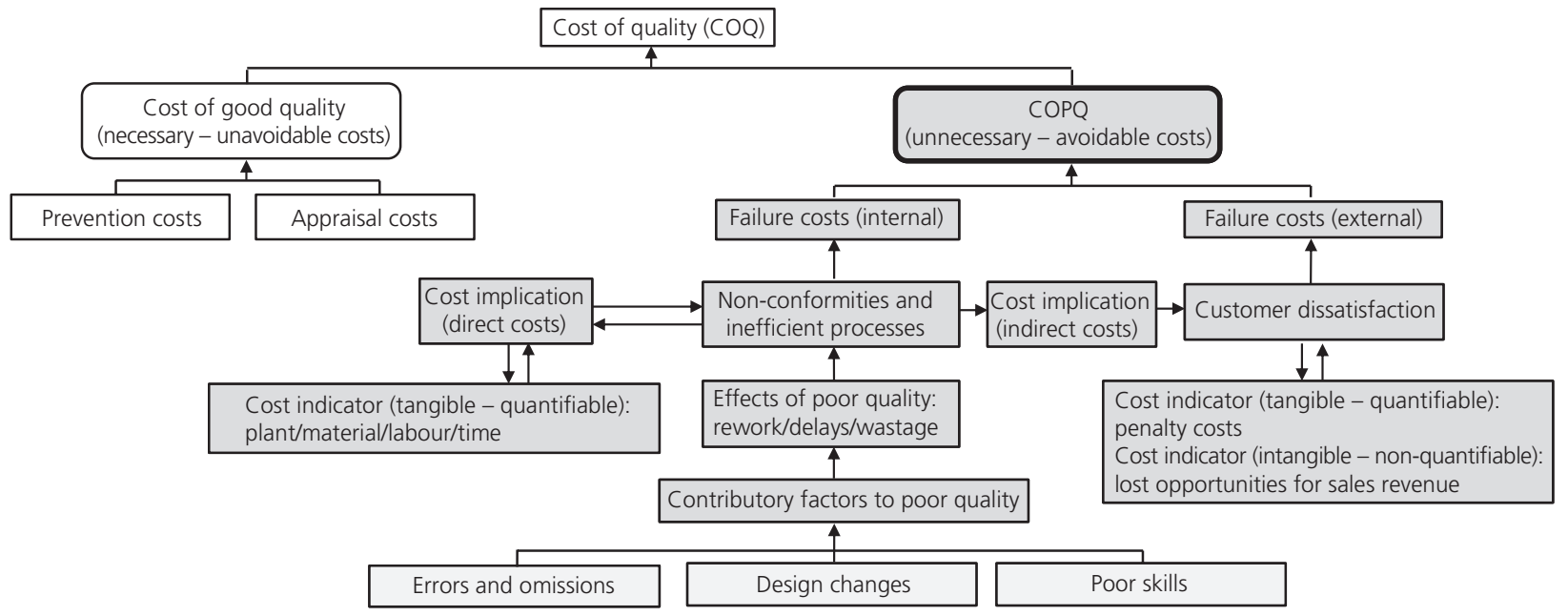

Figure 3. An integrated COPQ model 
Furthermore, none of the existing body of work has examined this impact. This study therefore intends to bridge this identified significant gap. Although none of the previous studies has investigated the impact of $\mathrm{KM}$ on COPQ or shown any empirical evidence of the extent of the impact, literature suggests that poor $\mathrm{KM}$ contributes to COPQ and that optimising $\mathrm{KM}$ - that is, harnessing and integrating knowledge across boundaries - can reduce $\mathrm{COPQ}$, thereby leading to improved project performance from the overall project management perspective, increased customer satisfaction and improved industry reputation. This study therefore set out to explore these areas.

\section{Research methodology}

An exploratory sequential mixed-methods approach was considered appropriate for the study in which the initial qualitative phase was used, first, to build an instrument that best fits the sample under study; second, to identify the appropriate research instruments for the follow-up quantitative phase; and, third, to specify variables that need to go into the quantitative study (Creswell, 2008; Tashakkori and Teddlie, 2010). As a philosophical underpinning for the mixed-methods approach, Patton (1990) and Tashakkori and Teddlie (2010) conveyed its importance of focusing attention on the research problem and then using pluralistic approaches to derive knowledge about the problem. The use of exploratory sequential mixed methods was based on the investigative nature of the research and the need to explore initially the views of practitioners on the extent of the impact of KM on COPQ based on their experiences on various projects. The data obtained from the findings were then analysed and used to plan into the quantitative phase. Semi-structured interviews and a questionnaire survey were utilised as qualitative and quantitative techniques of inquiry, respectively, and are further discussed in Sections 3.1 and 3.2.

\subsection{Design and analysis of the interviews}

The semi-structured interview was designed specifically for construction industry experts in the areas of KM, quality management, cost management, project management and design management (see Table 2). A non-probability sampling strategy was adopted in the selection of interviewees because of its suitability for in-depth qualitative research where the focus is to understand complex social phenomena (Creswell, 2009; Marshall, 1996). The interviewees were selected from communities of practice in industry and expert forums across the UK based on the eligibility criteria of project experience, organisational experience and job designation. The sample size progressively grew up to 25 interviewees, at which point saturation was reached, whereby data collection neither led to more information nor gave further insight into the study (Crouch and McKenzie, 2006). This sample size nevertheless falls within what is acceptable for qualitative research of this nature (Morse, 2003).

The interviewees have acquired years of experience in large construction organisations (companies with over 250 employees), in particular with main contractors, and have been involved in a diverse range of projects. Sixteen per cent of the interviewees have acquired over 30 years of experience; $28 \%$, between 20 and 30 years; $24 \%$, between 10 and 20 years; and $32 \%$, between 5 and 10 years. The main question posed to the interviewees was as follows: what is the impact of $\mathrm{KM}$ in reducing the cost of $(a)$ design changes, (b) errors and omissions and (c) poor skills? The interview data were analysed using a thematic approach (Braun and Clarke, 2006) which focused on identifying and describing both implicit and explicit ideas within the data - that is, themes.

According to Streubert and Carpenter (1999), qualitative research is trustworthy when it accurately represents the experience of the study participants. The four processes described by Lincoln and Guba (1985) for establishing trustworthiness are credibility, dependability, confirmability and transferability. These checks were applied to this study, as discussed in the following, to ensure the trustworthiness of the study.

\subsubsection{Credibility}

Lincoln and Guba (1985) suggested that to obtain credibility, five processes are involved. These include prolonged engagement, persistent observation, peer briefing, member checks and triangulation.

Prolonged engagement in the area under study was achieved by the number of interviews that were carried out and by returning to the participants in order to build on previous interviews. This also contributed towards building trust with the participants, learning about their current circumstances and culture, and being able to check against any seeming misinformation and distortions that might have been introduced by the researcher (Creswell, 1998).

\begin{tabular}{lclr}
\hline Area of expertise & Number of interviewees & Interviewee IDs & Percentage of intervis \\
\hline KM & 7 & A, C, D, E, G, J, R & 28 \\
Quality management & 4 & F, K, N, O & 16 \\
Cost management & 2 & I, W & 8 \\
Project management & 6 & L, M, P, T, U, V & 24 \\
Design management & 6 & B, H, Q, S, X, Y & 24
\end{tabular}


Peer debriefing provides a mechanism for a researcher to avail himself or herself to inquisitive questions by someone playing the 'devil's advocate' (Lincoln and Guba, 1985: p. 308) and further ensuring honesty. In this study, peer debriefing was achieved by liaising with one of the researcher's supervisors who played this part extremely well. He questioned the methods used as well as the meanings and interpretations of the communication.

Member checks were carried out in this study by returning to a number of participants and asking them to examine and comment on the interpretations and conclusions which were being drawn from the data. According to Lincoln and Guba (1985: p. 314)

\footnotetext{
The member check, whereby data, analytic categories, interpretations and conclusions are tested with members of those stake-holding groups from whom the data were originally collected, is the most crucial technique for establishing credibility. If the investigator is to be able to purport that his or her reconstructions are recognisable to audience members as adequate representations of their own (and multiple) realities, it is essential that they be given the opportunity to react to them.
}

Triangulation encourages the use of different sources of information methods and theories to provide supporting evidence. In this study the different sources of information used included information from the participants themselves, company documents and relevant literature.

\subsubsection{Dependability/confirmability}

Dependability is the qualitative researcher's equivalent of 'reliability'. Lincoln and Guba (1985) contended that there can be no dependability without credibility. Dependability is considered once the researcher has determined the credibility of the findings. Both the dependability and confirmability of a study may be addressed by the demonstration of an audit trail that records activities over time which another individual can follow. This audit trail would include all documentation: tapes, wave files, transcripts, memos and diagrams, in fact, everything concerned with the study. Lincoln and Guba (1985) also suggested that it is necessary that an auditor be able to judge the extent to which the researcher's values and biases may have influenced the findings.

However, Cutcliffe and McKenna (1999: p. 377) argued that this method does not leave room for 'hunches' or 'felt sense' of the emerging theory which can occur as the researcher becomes immersed in the data. They contend that it is difficult to demonstrate intuition and inspiration. It is in this regard that memos can be used as part of an audit trial. The report of this study has been written in as much detail as possible, with examples of the analytical processes used in order that judgement of its trustworthiness can be made.

As also recommended by Miles and Huberman (1994), coding checks were made by the academic supervisors of the study. Samples of transcripts were coded by an independent research colleague, and comparison was made with the coding generated by the researcher, and these agreed with each other.

\subsubsection{Transferability}

Transferability should enable other researchers to transfer information to other settings. This research has been described in detail, including the participants and the setting under study, therefore allowing others to determine whether the findings could be transferred to other situations with which they are familiar.

\subsubsection{Reproducibility}

Strauss and Corbin (1998) suggested that the ability to reproduce findings gives the original findings credibility. However, reproducing social phenomena can be difficult because it is nearly impossible to replicate the original conditions under which data were collected or to control all the variables that might possibly affect findings. Meanwhile, Strauss and Corbin (1998) argued that reproducibility can be achieved by adopting the same theoretical perspective of the original researcher, following the same general rules for data gathering and analysis and assuming a similar set of conditions. By doing so, the same problems and issues should arise from this subsequent inquiry, regardless of whether they are conceptualised and integrated a little differently.

To enhance reproducibility in this research, the analysis focused on drawing interpretation and meanings that are consistent with the data collected (Hatch, 2002). A six-step process based on Creswell's (2009) guide for qualitative data analysis was utilised as follows: (a) to organise and prepare the data for analysis, including transcription of audio recording into text format; $(b)$ to read through all the data to gain a general sense of the information and reflect on the overall meaning; $(c)$ to conduct analysis based on the selected theoretical approach and method; (d) to generate a description of the setting, identify themes from the coding and search for theme connections; (e) to represent the data within a research report; and $(f)$ to interpret the larger meaning of the data.

\subsection{Design and analysis of the questionnaire survey}

A questionnaire was designed to facilitate the collection of quantitative data related to the impact of $\mathrm{KM}$ on COPQ. The questionnaire design was based on the variables derived from the interviews on $\mathrm{KM}$ practices in construction projects. The questionnaire respondents were selected also by non-probability sampling, which was a deliberate selection of the most appropriate respondents, in particular KM practitioners in construction who could provide credible insight into the study. The respondents were selected based on their years of experience in the construction industry. By using online directories of $\mathrm{KM}$ communities of practice within construction, a list was drawn up of 250 research targets who were contacted and sent the questionnaire. The questionnaire contained closed-ended questions in which respondents were asked to rate the level of impact of 15 $\mathrm{KM}$ practices on the cost of $(a)$ design changes, $(b)$ errors and omissions and (c) poor skills. A 4-point Likert scale (Knight and 
Ruddock, 2008) was utilised to measure the level of impact as follows: 1 - strongly negative impact; 2 - negative impact; 3 positive impact; and 4 - strongly positive impact. A total of 114 valid responses were received, thereby putting the response rate at $46 \%$. The responses were collated and analysed using the SPSS statistical software.

The reliability of the research instrument is concerned with its consistency. This research used the Cronbach's alpha value in order to assess the internal consistency of the results across measures. The construct of this study had a Cronbach's alpha of $0 \cdot 886$. This implies a high degree of internal consistency in the responses to the individual measures. Alpha values above 0.7 are acceptable indicators of internal consistency as suggested in the literature (Nunnaly, 1978)

The mean values for the ratings of impact were calculated and ranked in descending order to identify the relative significance of the processes as well as those that have had the most and least impact on COPQ in practice.

\section{Findings}

The findings from the interviews and the questionnaire survey are presented in Sections 4.1 and 4.2, respectively.

\subsection{Findings from the interviews}

The findings are based on the recurrent themes that emerged from the analysis and commonality of responses across all interviewees wherein factors that are widespread and cut across all project types were identified. The findings are presented under three categories: $(a)$ the capture and exploitation of knowledge to reduce the errors and omissions, (b) the impact of $\mathrm{KM}$ on minimising the cost of design changes and (c) the impact of $\mathrm{KM}$ on sustaining skills.

\subsubsection{The capture and exploitation of knowledge to reduce the errors and omissions}

There was evidence of knowledge sharing at the personal, organisational and project levels.

Across the personal level, for example, interviewee D asserted that the team of experts within their organisation embarks on periodical knowledge-sharing sessions in order to ensure that knowledge does not reside in only one person but is spread across personnel, so that knowledge is retained in the organisation should any one choose to leave. Similarly, interviewee L stated that their organisation holds monthly toolbox talks in which team members share new insights with one another - for example, new methods and procedures of work. This has resulted in further investigating details surrounding why errors occur and how these could be eliminated.

At the organisational level, there was evidence of the use of techniques and technologies for knowledge storage, retrieval and sharing. According to interviewee $G$, their organisation has a knowledge bank and technical excellence groups. Their organisational knowledge and how it matches the challenges they face on projects is reviewed by a technical excellence group. They also have a number of publications for knowledge dissemination to the organisation's main functional and operational units in order to ensure that adequate lessons learnt are known and mistakes that have been made are not repeated. Another example of organisational-level KM was cited by interviewee Q, who stated that their organisation keeps an online technical query and lessonslearnt $\log$ from which personnel can externalise and internalise knowledge. This has reduced errors.

At the project level, there was evidence of integration, collaborative working and knowledge sharing and retention within some supply chains. According to interviewee E, 'we ensure that we retain most of our supply chain of about 60 companies and use them from project to project. The benefit of this is that significant project knowledge is retained within the chain and there is a level of trust within the chain since they can rest assured that they will be working together for a long time. The environment of trust therefore encourages knowledge sharing among parties'. Little evidence was found of industry-level KM impact.

\subsubsection{The impact of KM on minimising the cost of design changes}

KM was found to have the most impact on the cost of design changes at the organisational and project levels. Despite the perception that design change is inevitable during the construction phase of a project, it was found that implementing $\mathrm{KM}$ had an impact in reducing client- and other supply chain-related changes. Although interviewee $\mathrm{E}$ stated that 'design is an iterative process therefore change is inevitable', it was found that the early involvement of, and collaboration among, supply chain organisations had a positive impact in reducing the incidences and cost of design changes. According to interviewee $\mathrm{H}$, subcontractors are brought in during the conceptual stage of projects, which helps enormously, as they are able to make contributions to identify all the work that is required for a particular project and the cost implications. Similarly, interviewee I commented that '[i]f you can get all the parties involved to buy in from the design stage all the way through the project, you sort of eliminate stupidity waste'.

\subsubsection{The impact of KM on sustaining skills}

There was evidence of knowledge sharing and knowledge transfer through mentoring in order to retain the knowledge of experienced staff and to improve the skills of the less experienced ones. According to interviewee $\mathrm{O}$, their organisation has a mentoring and line management system which reduces knowledge erosion or knowledge loss. Similarly, interviewee D commented that 'people always work together in a group; basically for every position you find out that there are two or three other people that are involved. At times, unfortunately, if we lose a good member of staff, another person is there as capable as the other guy leaving. A loss of someone probably does not mean that the knowledge is being lost'. 
There was a general view that the construction industry is project based and that every project is unique, therefore adversely affecting the impact of KM. According to interviewee J, "we are the only industry that is like a mobile factory. Other industries have a base and a facility. Our business is the only business where the construction site is the factory. When you finish, the factory is taken away and the building is left'. Perhaps this effect is felt by personnel and teams who have to split and move on to other different projects. Interviewee A gave a related example, 'At the end of this scheme (infrastructure project), there was a review on what has gone well and what has not gone as well. When you come to the next scheme or the same scheme in 5 years time, unfortunately the people who have gone through that painful experience on the earlier job are not around with the company or are not the people allocated with the experience of that to the new scheme'.

\subsubsection{Variables informing the questionnaire survey}

The common theme that emerged from the interviewees was that $\mathrm{KM}$ has a positive impact in reducing COPQ. However, none of the interviewees indicated the level of this impact. It was found that organisations neither measured nor tracked this impact, which is a fundamental step in optimising $\mathrm{KM}$ to reduce COPQ. According to interviewee $\mathrm{C}$, 'If you cannot measure you cannot manage'. It was discovered that organisations did not have a systematic, structured approach to KM with measurable outputs on COPQ reduction. Interviewee $\mathrm{S}$, for example, commented that 'although we do a lot of knowledge management work, we don't formally have tools or structured methods'. At the industry level, interviewee A commented that 'something that the industry lacks is a common data capture format. I think from an industry perspective if we had a common method of collecting data so they could be aggregated and we could share from that, it would help. If we could collect data in a common fashion then it would be easier for the industry to aggregate their data and learn from it'.

The findings from the interviews therefore raised two further research questions. (a) What is the level of impact of KM on COPQ? (b) Which aspects of KM have had the greater impact in reducing COPQ? These questions were addressed, first, by extracting variables from the interviews on $\mathrm{KM}$ practices in organisations and, second, by carrying out a questionnaire survey with a wider sample of practitioners to rate the impact of these practices in reducing COPQ. Fifteen variables were identified that cut across all interviewees. These variables and their brief descriptions are presented in Table 3.

\subsection{Findings of the questionnaire survey}

The findings from the questionnaire survey are presented in Table 4, which shows KM practices and their impact on design changes, errors and omissions and poor skills. It is noteworthy that the ratings were based on the respondents' individual experiences on various projects and not on a particular case study. Their ratings by way of a Likert scale reflect their individual perceptions of the impact of $\mathrm{KM}$ on COPQ, which was considered acceptable for this initial exploratory study. A subsequent study will focus on specific project cases and utilise a single point of reference by using several measurable factors of impact, for instance, profit, turnover and reduced project costs.

The external and construct validity of the survey was generally improved by ensuring that (Fowler, 2002; Mitchell and Jolley, 2001) the survey instrument was sufficient in detail and scope and focused on the objectives of the study; the questions were clear, intelligible and logically sequenced, and matched the knowledge base of target respondents; and all the definitions were well articulated.

The mean rating of each variable was computed based on the Likert data obtained from the 114 respondents. The variables were also ranked, based on these mean ratings, where the minimum and maximum ratings of all the variables fell between 3 and 4 on the Likert scale, which signified a 'strong positive impact' of KM practices in reducing COPQ. The three highest-ranking variables that impact design changes were knowledge sharing - early involvement (3.5175); knowledge creation (3.5088); and knowledge capture - project to project $(3 \cdot 3772)$. The three lowestranking variables that impact design changes were knowledge dissemination - communities of practice (3.1316); knowledge storage $(3 \cdot 1316)$; and knowledge transfer - mentoring $(3 \cdot 1053)$.

The three highest-ranking variables that impact errors and omissions were knowledge capture - project to organisation (3.5); knowledge champions (3.4649); and knowledge sharing among project team $(3 \cdot 4561)$. The three lowest-ranking variables were knowledge codification - personnel to document (3.1491); knowledge dissemination - communities of practice $(3 \cdot 1404)$; and knowledge storage $(3 \cdot 1404)$. The three highest-ranking variables that impact poor skills were knowledge transfer mentoring (3.6053); knowledge transfer - apprenticeships (3.6053); and knowledge identification (3.5351). The three lowestranking variables were knowledge dissemination - publications $(3 \cdot 1228)$; knowledge codification - project to document $(3 \cdot 1140)$; and knowledge capture - project to project $(3 \cdot 1140)$.

The aggregate of the mean rankings for design changes, errors and omissions and poor skills was computed in order to find the overall ranking of the impact of KM practices in reducing COPQ (Table 5). The three highest-ranking KM practices that impact on the reduction of COPQ were knowledge transfer - apprenticeships (3.3480); knowledge transfer - mentoring (3.3421); and knowledge capture - personnel to organisation (3.3304). The three lowest-ranking KM practices were knowledge codification project to document $(3 \cdot 1520)$; knowledge storage $(3 \cdot 1404)$; and knowledge dissemination - communities of practice $(3 \cdot 1404)$.

\section{Discussion of findings}

It was established in this study that projects are still plagued with inefficiencies, repetition of mistakes and non-transfer of lessons learnt, thereby contributing to unnecessary cost of redoing processes that were implemented incorrectly the first time. The findings support previous work by Al-Ghassani et al. (2004), Egbu 

interviews

Description

1 Knowledge champions

2 Knowledge identification

3 Knowledge capture - personnel to organisation

4 Knowledge capture - project to organisation

5 Knowledge capture - project to project

6 Knowledge codification - personnel to document

Facilitators or coordinators of KM initiatives on projects or within organisation Recognising and selecting the sources and types of knowledge with specific value elements; knowing 'where' to find 'what' knowledge for 'which' purpose; identifying the critical knowledge that might be at risk in the organisation - for example, as a result of downsizing or resignations

Externalisation - that is, process of converting personal knowledge to organisational knowledge; capturing 'know-how' from individuals in a way that it can be reused by the organisation

Capturing knowledge from past or current projects and contributing to the organisational knowledge base

Capturing knowledge from one project for use on another project; capturing best practice or lessons learnt from one project to the other

Process of converting personal knowledge of individuals into documents or other explicit formats

7 Knowledge codification - project to Preserving, maintaining and indexing project knowledge for easy search and retrieval document

8 Knowledge storage

9 Knowledge dissemination communities of practice

10 Knowledge dissemination publications

11 Knowledge sharing among project team

12 Knowledge sharing - early involvement

13 Knowledge transfer apprenticeships

14 Knowledge transfer - mentoring

15 Knowledge creation
Creating an organisational or project knowledge base accessible to all personnel Knowledge dissemination through face-to-face interactions or knowledge experts

Knowledge dissemination through case study publications of best practice in $\mathrm{KM}$

Periodical knowledge sharing practices among project team members

Involving the supply chain organisations at the earliest stages of a project

Transfer of tacit knowledge from experienced personnel to less experienced ones through apprenticeship programmes

Transfer of tacit knowledge from experienced personnel to less experienced ones through mentoring programmes

Organisational ability to bring into existence and originate new knowledge continuously through the interactions between supply chain and project team personnel

Table 3. KM practices across personal, organisational, project and

industry levels

(2005), Suresh et al. (2008), Carrillo et al. (2013) and Ren et al. (2013). This confirms some of the prevalent project challenges faced by organisations within supply chains such as tight project schedules and limited budgets (Ruan et al., 2012; Zin and Egbu, 2011). KM was found to have a positive impact in reducing COPQ. However, there was a new insight that organisations could not quantify COPQ and neither could they measure the extent of the impact of KM on COPQ. The questionnaire survey therefore was useful in rating the level of this impact.

The highest-ranking KM practices that impact the reduction of COPQ were knowledge transfer - apprenticeships and knowledge transfer mentoring. This reveals the importance of the management of the tacit knowledge of employees to ensure in particular that adequate knowledge is transferred from more experienced employees to less experienced ones. A very useful interface of SECI (Nonaka and Takeuchi, 1995; Nonaka and Toyama, 2005; Polanyi, 1966) is therefore socialisation. Knowledge capture - personnel to the organisation also ranked high in terms of impact. This could mean that the personnel are successfully 'externalising' their tacit knowledge and converting it into more explicit formats, thereby contributing to their organisational knowledge base (Suresh, 2006).

In terms of impacting $\mathrm{COPQ}$, the lowest-ranking $\mathrm{KM}$ practices were knowledge codification - project to document; knowledge storage; and knowledge dissemination - communities of practice. Knowledge codification and storage are closely linked. While codification deals with preserving, maintaining and indexing project knowledge for easy search and retrieval, storage deals with creating an organisational or project knowledge base that is accessible to all its 


\begin{tabular}{|c|c|c|c|c|c|c|c|c|}
\hline \multirow[t]{2}{*}{ Impact of KM practices on COPQ } & \multicolumn{2}{|c|}{ Design changes } & \multicolumn{2}{|c|}{ Errors and omissions } & \multicolumn{2}{|c|}{ Poor skills } & \multicolumn{2}{|c|}{ COPQ } \\
\hline & Mean & Ranking & Mean & Ranking & Mean & Ranking & Mean & Ranking \\
\hline Knowledge champions & $3 \cdot 1667$ & 11 & $3 \cdot 4649$ & 2 & $3 \cdot 2982$ & 5 & $3 \cdot 3099$ & 7 \\
\hline Knowledge identification & $3 \cdot 1579$ & 12 & $3 \cdot 1930$ & 11 & $3 \cdot 5351$ & 3 & $3 \cdot 2953$ & 9 \\
\hline Knowledge capture - personnel to organisation & $3 \cdot 2018$ & 7 & $3 \cdot 2632$ & 7 & $3 \cdot 5263$ & 4 & $3 \cdot 3304$ & 3 \\
\hline Knowledge capture - project to organisation & $3 \cdot 2456$ & 6 & $3 \cdot 5000$ & 1 & $3 \cdot 2368$ & 7 & $3 \cdot 3275$ & 4 \\
\hline Knowledge capture - project to project & $3 \cdot 3772$ & 3 & $3 \cdot 2632$ & 6 & $3 \cdot 1140$ & 14 & $3 \cdot 2515$ & 10 \\
\hline Knowledge codification - personnel to document & $3 \cdot 2018$ & 7 & $3 \cdot 1491$ & 13 & $3 \cdot 2544$ & 6 & $3 \cdot 2018$ & 12 \\
\hline Knowledge codification - project to document & $3 \cdot 1754$ & 9 & $3 \cdot 1667$ & 12 & $3 \cdot 1140$ & 14 & $3 \cdot 1520$ & 13 \\
\hline Knowledge storage & $3 \cdot 1316$ & 13 & $3 \cdot 1404$ & 14 & $3 \cdot 1491$ & 10 & $3 \cdot 1404$ & 14 \\
\hline Knowledge dissemination - communities of practice & $3 \cdot 1316$ & 13 & $3 \cdot 1404$ & 14 & $3 \cdot 1491$ & 10 & $3 \cdot 1404$ & 14 \\
\hline Knowledge dissemination - publications & $3 \cdot 2632$ & 5 & $3 \cdot 2281$ & 9 & $3 \cdot 1228$ & 12 & $3 \cdot 2047$ & 11 \\
\hline Knowledge sharing among project team & $3 \cdot 3070$ & 4 & $3 \cdot 4561$ & 3 & $3 \cdot 2105$ & 8 & $3 \cdot 3245$ & 5 \\
\hline Knowledge sharing - early involvement & $3 \cdot 5175$ & 1 & $3 \cdot 2281$ & 9 & $3 \cdot 1842$ & 9 & $3 \cdot 3099$ & 7 \\
\hline Knowledge transfer - apprenticeships & $3 \cdot 1754$ & 9 & $3 \cdot 2632$ & 7 & $3 \cdot 6053$ & 1 & $3 \cdot 3480$ & 1 \\
\hline Knowledge transfer - mentoring & $3 \cdot 1053$ & 15 & $3 \cdot 3158$ & 5 & $3 \cdot 6053$ & 1 & $3 \cdot 3421$ & 2 \\
\hline Knowledge creation & $3 \cdot 5088$ & 2 & $3 \cdot 3333$ & 4 & $3 \cdot 1228$ & 12 & $3 \cdot 3216$ & 6 \\
\hline Mean & $3 \cdot 2445$ & & $3 \cdot 2737$ & & $3 \cdot 2819$ & & & \\
\hline
\end{tabular}

Table 4. Impact of KM practices in reducing COPQ on construction projects

personnel. It can be inferred that no matter the amount of explicit knowledge available to an organisation, it is useless if their personnel do not 'pull', 'internalise' and, in particular, use it. It was thus not surprising that the aspect of personalisation approach to $\mathrm{KM}$ appeared to be more effective than the codification approach. What is surprising, however, is that knowledge dissemination through

\begin{tabular}{ll}
\hline Impact of KM practices on COPQ & Mean \\
\hline Knowledge transfer - apprenticeships & $3 \cdot 3480$ \\
Knowledge transfer - mentoring & $3 \cdot 3421$ \\
Knowledge capture - personnel to organisation & $3 \cdot 3304$ \\
Knowledge capture - project to organisation & $3 \cdot 3275$ \\
Knowledge sharing among project team & $3 \cdot 3245$ \\
Knowledge creation & $3 \cdot 3216$ \\
Knowledge champions & $3 \cdot 3099$ \\
Knowledge sharing - early involvement & $3 \cdot 3099$ \\
Knowledge identification & $3 \cdot 2953$ \\
Knowledge capture - project to project & $3 \cdot 2515$ \\
Knowledge dissemination - publications & $3 \cdot 2047$ \\
Knowledge codification - personnel to document & $3 \cdot 2018$ \\
Knowledge codification - project to document & $3 \cdot 1520$ \\
Knowledge storage & $3 \cdot 1404$ \\
Knowledge dissemination - communities of practice & $3 \cdot 1404$
\end{tabular}

Table 5. Overall ranking of the impact of KM practices in reducing COPQ communities of practice ranked lowest, contrary to the notion of the effectiveness of the personalisation approach.

\section{Way forward}

The KM practices with high impact on COPQ are presented in Table 4. These can be used to develop a flow chart that shows how these practices feed into COPQ, as shown in Figure 4. In as much as these top contributors to COPQ are significant, other notable but not-so-highly rated contributors should not be overlooked. However, Figure 4 stands out as a prompter to organisations to undertake KM proactively on a regular basis and to measure and track COPQ specifically. A framework for enabling organisations to undertake this $\mathrm{KM}$ activity regularly is proposed in Figure 5, which is based on the literature review of $\mathrm{KM}$ and $\mathrm{COPQ}$, followed by the empirical data which were collected and analysed in this study.

Figure 5 consists of five components labelled from A to E. Component $\mathrm{A}$ forms the core of the research and shows the logic between $\mathrm{KM}$ and COPQ. The present state of affairs is that COPQ is prevalent and perhaps stems from poor KM. Optimising $\mathrm{KM}$ therefore is expected to cause a reduction in COPQ.

Component $\mathrm{B}$ is derived from the qualitative and quantitative data analyses, which concluded that in order to optimise KM to reduce COPQ, there are existing key barriers which need to be overcome. Ways of dealing with these barriers include adopting a KM-supportive procurement strategy; appointing knowledge champion(s) on every project; creating a project knowledge base; 


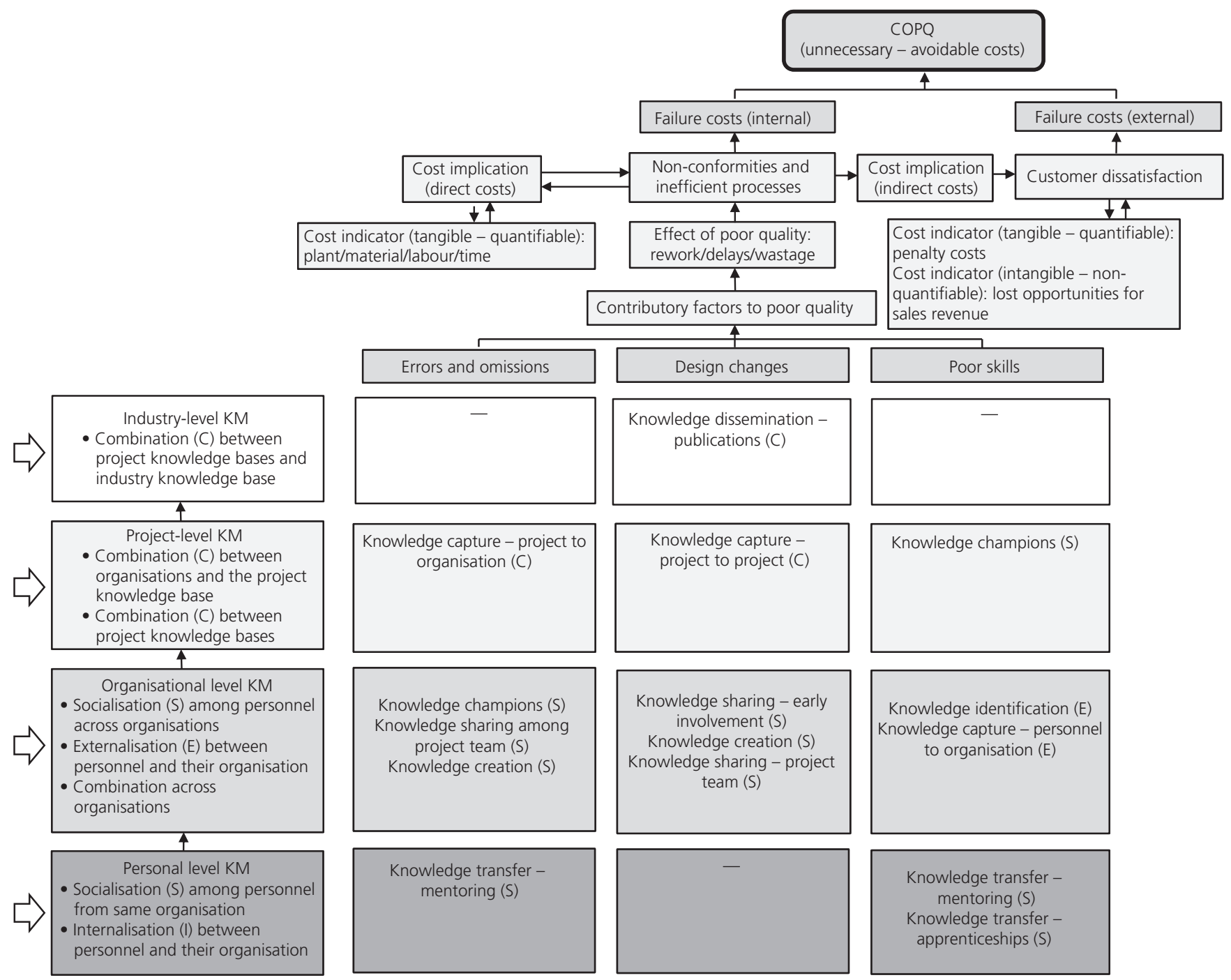

Figure 4. Impact of KM in reducing COPQ (high-impact KM processes)

allocating adequate time and budget for KM initiatives; and encouraging a KM-supportive organisational and project culture.

Component $\mathrm{C}$ is derived from the outcomes of the extensive literature review and qualitative data analysis. An integrated COPQ model presented in Figure 3 shows how all aspects of previous studies of COPQ are interlinked, in particular the causes, effects and cost implications of COPQ. One of the conclusions from the qualitative data analysis is that organisations do not quantify COPQ and neither do they know how to quantify it. A key step to managing COPQ, however, is the ability to quantify it. Therefore, the integrated COPQ model informed component C, which is to quantify COPQ through four steps: $(a)$ identify the contributory factors to COPQ and classify these into design changes, errors and omissions, poor skills and other projectspecific classifications; $(b)$ categorise the effects of the factors into rework, delays or wastage; (c) calculate the cost implications in terms of plant, material, labour, time or penalties; and (d) calculate the total COPQ as a percentage of total project cost.

Component D relates to the assessment of the impact of $\mathrm{KM}$ on COPQ and is derived from the critical review of literature and the findings from both the qualitative and quantitative data analyses, which concluded that despite the current use of KM initiatives, organisations do not fully assess the impact of KM on COPQ. A five-step approach is presented in component D as follows: (a) review $\mathrm{KM}$ initiatives as implemented at the personal, organisational, project and industry levels before the COPQ issues; (b) review the $\mathrm{KM}$ initiatives' post-COPQ issues; (c) implement new KM initiatives or reinforce ongoing initiatives to reduce COPQ; $(d)$ calculate the total cost of $\mathrm{KM}$ initiatives as a percentage of the total project cost; and (e) calculate the impact of $\mathrm{KM}$ on $\mathrm{COPQ}$ as a percentage cost of $\mathrm{KM}$ investments against the percentage reduction in COPQ. 


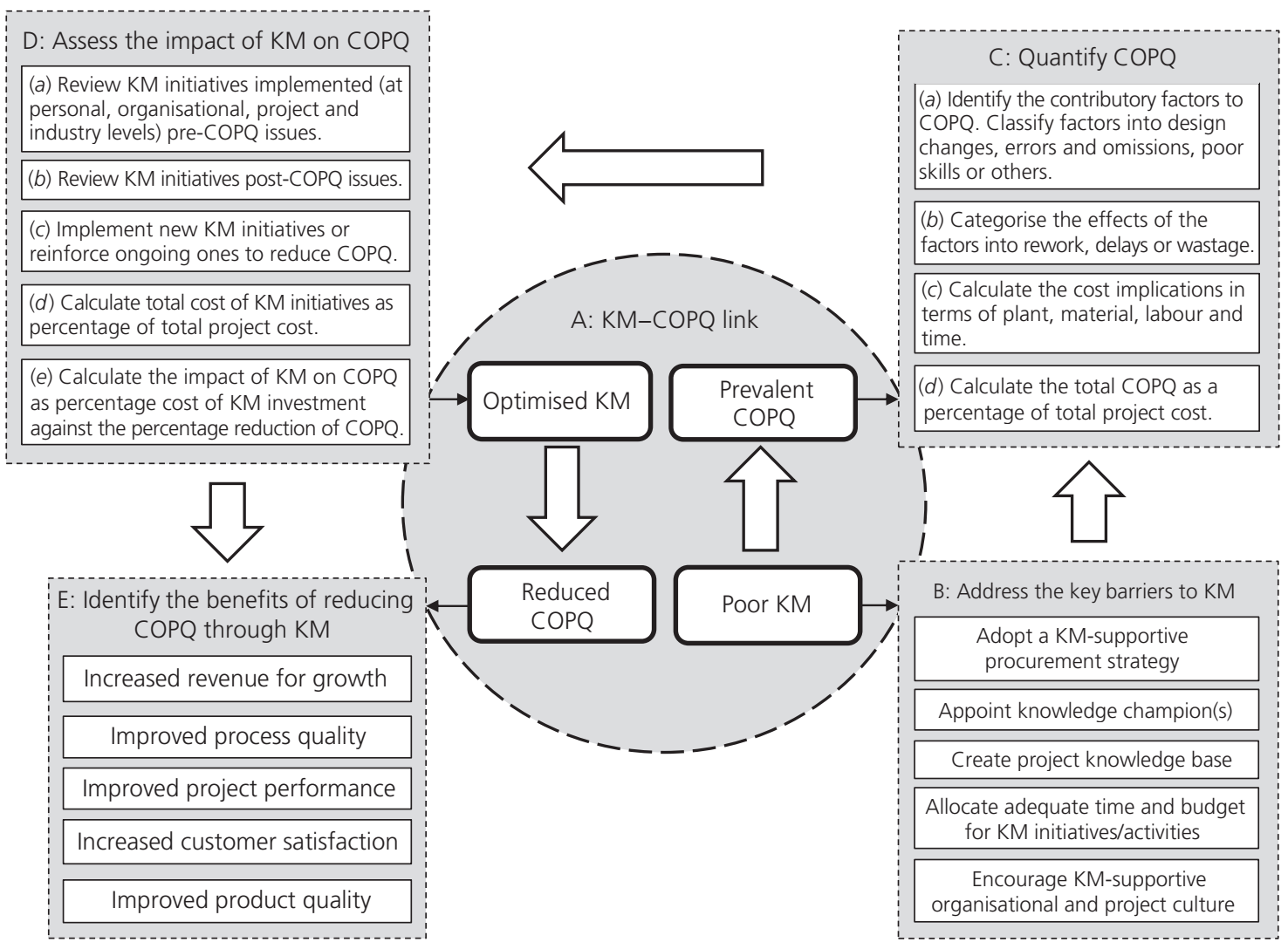

Figure 5. KM framework for reducing COPQ on construction

projects

Component $\mathrm{E}$ is derived from both literature and collection and analysis of primary data. The benefits associated with reducing COPQ include increased revenue for growth, improved process quality, improved project performance, increased customer satisfaction and improved product quality. There are so many other benefits that can be realised from reducing COPQ through $\mathrm{KM}$; the ones presented in the framework are those that ranked highest in the quantitative data analysis.

The framework is a cyclic process which should be implemented periodically - for example, monthly - unlike some current practices where $\mathrm{KM}$ is reviewed at the end of the project phase. This assessment should be conducted regularly, in particular while a project is still ongoing. This enables knowledge champions or knowledge managers to track lessons learnt and avoid the repetition of mistakes.

\section{Conclusions}

This study was exploratory in nature and examined the broad domains of KM and COPQ. The output of the study led to a new understanding of the impact of $\mathrm{KM}$ on COPQ. The common theme that emerged from all interviewee responses was that KM has a positive impact in reducing COPQ; however, none of the interviewees could evaluate the extent of this impact.
It was subsequently established from the questionnaire survey that the three highest-ranking $\mathrm{KM}$ practices that impact the reduction of COPQ were knowledge transfer - apprenticeships; knowledge transfer - mentoring; and knowledge capture personnel to organisation. The three-lowest ranking $\mathrm{KM}$ practices were knowledge codification - project to document; knowledge storage; and knowledge dissemination - communities of practice.

This paper contributes to the body of knowledge in the area of $\mathrm{KM}$ and COPQ by providing new valuable insights for industry practitioners and academics. It also presents a new KM model for harnessing and integrating knowledge across personal, organisational, project and industry boundaries (Figure 1). Further, it presents the KM process/subprocess classification (Figure 2). There was evidence of harnessing and integrating knowledge utilising KM processes (e.g. knowledge sharing and knowledge codification) and tools (e.g. knowledge bases and virtual collaborative workspaces). The paper also presents a holistic approach to COPQ by integrating elements of previous studies in areas such as rework, delays and wastage on projects (Figure 3). No matter the amount of explicit knowledge available to an organisation, it is useless if their personnel do not pull, internalise and, in particular, use it. 
Management, Procurement and Law

Volume 170 Issue MP1
Impact of knowledge management

on construction projects

Suresh, Olayinka, Chinyio and Renukappa
It was found that KM currently has not been optimised to reduce COPQ due to a number of barriers. Optimising KM to reduce COPQ involves developing performance metrics to assess the impact of $\mathrm{KM}$ on COPQ on projects; appointing knowledge champions to facilitate KM activities to reduce COPQ; adopting a positive organisational culture towards $\mathrm{KM}$; allocating adequate time for KM activities on projects; allocating adequate budget for $\mathrm{KM}$ activities on projects; and selecting procurement strategies that support and facilitate KM.

The study provides a practice guide for reducing COPQ (Figure 5) which encompasses five components. Other new insights from the findings include the need to develop toolkits to track the impact of $\mathrm{KM}$ on COPQ on projects and the need to adopt procurement strategies that support $\mathrm{KM}$ at the personal, organisational, project and industry levels.

The recommendations for practitioners are closely connected to the findings from the fieldwork phase of this research. This is in particular useful for project managers, knowledge champions, quality managers and continuous improvement managers within the construction supply chain. The study has practical relevance and application in providing construction organisations with the insight that investing in KM and quality management techniques, technologies and systems is important, but what is more important is the ability to track the impact of the investment in cost terms. Organisations need to understand and accept that there is an endemic COPQ problem which urgently needs to be addressed. Organisations need to adopt a holistic approach and a robust methodology in quantifying COPQ such as the one presented in this study. Quantifying COPQ forms the basis on which to measure the impact of KM on COPQ. Performance metrics should be developed to assess the impact of KM on COPQ in projects.

\section{REFERENCES}

Abdul-Rahman H (1995) The cost of non-conformance during a highway project: a case study. Construction Management and Economics 13(1): 23-32.

Al-Ghassani AM, Kamara JM, Anumba CJ and Carrillo PM (2004) An innovative approach to identifying knowledge management problems. Journal of Engineering, Construction and Architectural Management 11(5): 349-357.

Anand G, Ward PT and Tatikonda MV (2010) Role of explicit and tacit knowledge in Six Sigma projects: an empirical examination of differential project success. Journal of Operations Management 28(4): 303-315.

Armbrecht FMR, Chapas RB and Chappelow CC (2001) Knowledge management in research and development. Research-Technology Management 44(4): 28-48.

Behin D (2005) Knowledge Management at McKinsey. The Strategic Knowledge Management Forum. Osney Media, London, UK.

Bhatt GD (2001) Knowledge management in organisation: examining the interaction between technology, techniques and people. Journal of Knowledge Management 5(1): 68-75.
Braun V and Clarke V (2006) Using thematic analysis in psychology. Qualitative Research in Psychology 3(2): 77-101.

Burati JL, Farrington JJ and Ledbetter WB (1992) Causes of quality deviations in design and construction. Journal of Construction Engineering and Management 118(1): 34-49.

Carrillo P and Chinowsky P (2006) Exploiting knowledge management: the engineering and construction perspective. Management in Engineering 22(1): 2-10.

Carrillo P, Ruikar K and Fuller P (2013) When will we learn? Improving lessons learned practice in construction. International Journal of Project Management 31(4): 567-578.

Chatterjee S (2013) Simple rules for designing business models. California Management Review 55(2): 97-124.

Chung HW (1999) Understanding Quality Assurance in Construction: a Practical Guide to ISO 9000 for Contractors. Routledge, London, UK.

Cnuddle M (1991) Lack of quality in construction - economic losses. Proceedings of 1991 European Symposium on Management, Quality and Economics in Housing and Other Building Sectors, pp. 508-515.

Collison C and Parcell G (2001) Learning to Fly: Practical Lessons from One of the World's Leading Knowledge Companies. Capstone, Oxford, UK.

Coombs R and Hull R (1997) Knowledge Management Practices and Path Dependency in Innovation. Institute of Science and Technology, University of Manchester, Manchester, UK, CRIC Discussion Paper no. 2.

Cox R (1999) Representation construction, externalised cognition and individual differences. Learning and Instruction 9(4): 343-363.

Creswell JW (1998) Qualitative Inquiry and Research Design: Choosing among Five Traditions. Sage, London, UK.

Creswell JW (2008) Educational Research: Planning, Conducting, and Evaluating Quantitative and Qualitative Research. Pearson/Merrill Prentice Hall, Upper Saddle River, NJ, USA.

Creswell JW (2009) Research Design: Qualitative and Mixed Methods Approaches. Sage, London, UK.

Crosby PB (1979) Quality Is Free: the Art of Making Quality Certain. McGraw-Hill, New York, NY, USA.

Crouch M and McKenzie H (2006) The logic of small samples in interview based qualitative research. Social Science Information 45(4): 483-499.

Cutcliffe JR and McKenna HP (1999) Establishing the credibility of qualitative research findings: the plot thickens. Journal of Advanced Nursing 30(2): 374-384.

Davenport TH and Prusak L (1998) Working Knowledge. Harvard Business School Press, Boston, MA, USA.

Drucker PF (1999) Management Challenges for the 21st Century. Elsevier, New York, NY, USA.

Egbu CO (2005) Knowledge management as a driver for innovation. In Knowledge Management in Construction (Anumba CJ, Egbu CO and Carrillo PM (eds)). Blackwell Publishing, Oxford, UK, pp. 121-131.

Egbu C, Gaskell C and Howes J (2001) The role of organisational culture and motivation in the effective utilisation of 
information technology for teamworking in construction. Proceedings of the 17th Annual Conference of the Association of Researchers in Construction Management (ARCOM), Salford, UK, vol. 1, pp. 91-100.

Feigenbaum AV (1986) Total Quality Control. McGraw-Hill, New York, NY, USA.

Fowler FJ (2002) Survey Research Methods, 3rd edn. Sage, Thousand Oaks, CA, USA.

Garstenauer A, Blackburn T and Olson B (2014) A knowledge management based approach to quality management for large manufacturing organizations. Engineering Management Journal 2(4): 47-58.

Hatch JA (2002) Doing Qualitative Research in Education Settings. State University of New York Press, Albany, NY, USA.

Hislop D (2005) Knowledge Management in Organisations. Oxford University Press, Oxford, UK.

Holsapple CW and Joshi KD (2000) An investigation of factors that influence the management of knowledge in organizations. Journal of Strategic Information Systems 9(2-3): 235-261.

Holthouse D (1999) Ten knowledge domains: model of a knowledge-driven company? Knowledge and Process Management 6(1): 3-8.

Hwang B (2009) Identifying key sources of rework affecting construction cost performance. Proceedings of RICS COBRA Research Conference, Cape Town, South Africa, pp. 138-149.

ISO (International Organization for Standardization) (2005) ISO 9000: 2005: Quality management systems - fundamentals and vocabulary. ISO, Geneva, Switzerland.

Jashapara A (2011) Knowledge Management: an Integrated Approach. Financial Times Prentice Hall, Harlow, UK.

Josephson PE and Hammarlund Y (1999) The causes and costs of defects in construction: a study of seven building projects. Automation in Construction 8(6): 681-687.

Juran JM and Godfrey AB (1998) Quality in Japan. McGraw-Hill Professional Publishing, Blacklick, OH, USA.

Juran JM and Godfrey AB (1999) Juran's Quality Handbook, 5th edn. McGraw-Hill Professional Publishing, New York, NY, USA.

Kano N, Seraku N, Takahashi F and Tsuji S (1984) Attractive quality and must-be quality. Journal of the Japanese Society for Quality Control 14(2): 147-156.

Knight A and Ruddock L (2008) Advanced Research Methods in the Built Environment. Blackwell Publications, Chichester, UK.

Liebowitz J (1997) The Handbook of Applied Expert Systems. CRC Press, Washington, DC, USA.

Liebowitz J (1999) Knowledge Management Handbook. CRC Press, Boca Raton, FL, USA.

Lincoln YS and Guba EG (1985) Naturalistic Inquiry. Sage, Newbury Park, CA, USA.

Love P (2002) Influence of project type and procurement method on rework costs in building construction projects. Journal of Construction Engineering and Management 128(1): 18-29.

Love PED and Li H (2000) Quantifying the causes and costs of rework in construction. Construction Management and Economics 18(4): 479-490.
Love PED and Edwards D (2005) Calculating total rework costs in Australian construction projects. Civil Engineering and Environmental Systems 22(1): 11-27.

Love PED, Mandal P and Li H (1999) Determining the causal structure of rework influences in construction. Construction Management and Economics 17(4): 505-517.

Love PED, Zahir F and David JE (2004) A rework reduction model for construction projects. IEEE Transactions on Engineering Management 51(4): 426-440.

Love PD, Edwards DJ, Watson H and Davis P (2010) Rework in civil infrastructure projects: determination of cost predictors. Journal of Construction Engineering and Management 136(3): 275-282.

Lytras M, Pouloudi A and Poulymenakou A (2002) Knowledge management convergence: expanding learning frontiers. Journal of Knowledge Management 6(1): 40-51.

Marshall MN (1996) Sampling for qualitative research. Family Practice 13(6): 522-525.

Miles MB and Huberman AM (1994) Qualitative Data Analysis: an Expanded Sourcebook. Sage, London, UK.

Mitchell M and Jolley J (2001) Research Design Explained, 4th edn. Harcourt College Publishers, San Diego, CA, USA.

Morse JM (2003) Principles of mixed methods and multi-method research design. In Handbook of Mixed Methods in Social \& Behavioural Research (Tashakkori A and Teddlie C (eds)). Sage, Thousand Oaks, CA, USA, pp. 189-208.

Nonaka I and Takeuchi H (1995) The Knowledge-Creating Company: How Japanese Companies Create the Dynamics of Innovation. Oxford University Press, New York, NY, USA.

Nonaka I and Toyama R (2005) The theory of the knowledgecreating firm: subjectivity, objectivity and synthesis. Industrial and Corporate Change 14(3): 419-436.

Nunnaly J (1978) Psychometric Theory. McGraw-Hill, New York, NY, USA.

Nylén KO (1996) Cost of Failure in a Major Civil Engineering Project. Licentiate thesis, Division of Construction Management and Economics, Department of Real Estate and Construction Management, Royal Institute of Technology, Stockholm, Sweden.

O’Dell C and Grayson J (1998) If only we knew what we know: identification and transfer of internal best practices. California Management Review 40(3): 154-165.

Olayinka R, Suresh S, Chinyio E and Proverbs D (2011) A critique on the definitions of 'quality' in the construction industry. Proceedings of the 10th International Post Graduate Research Conference (IPGRC), Salford, UK, pp. 217-283.

Patton MQ (1990) Qualitative Research and Evaluation Methods, 2nd edn. Sage, Newbury Park, CA, USA.

Polanyi M (1966) The Tacit Dimension. Routledge and Kegan Paul, London, UK.

Preece J (2001) Online Communities: Designing Usability, Supporting Sociability. Wiley, Chichester, UK.

Ren ZZ, Shen GQ and Xue XL (2013) Failure caused by inappropriate construction methods: an expensive lesson. Journal of Management in Engineering 29(1): 25-34. 
Robinson HS, Carrillo PM, Anumba CJ and Al-Ghassani AM (2001) Knowledge management: towards an integrated strategy for construction project organisations. Proceedings of the 4th European Project Management Conference (PMI), London, UK (CD-ROM).

Rosenfeld Y (2009) Cost of quality versus cost of non-quality in construction: the crucial balance. Construction Management and Economics 27(2): 107-117.

Ruan X, Ochieng EG, Price AF and Egbu CO (2012) Knowledge integration process in construction projects: a social network analysis approach to compare competitive and collaborative working. Construction Management and Economics 30(1): 5-19.

Shapiro G (1999) Inter-project Knowledge Capture and Transfer: an Overview of Definitions Tools and Practices. Economic and Social Research Council, Swindon, UK, CoPS Innovation Centre Working Paper no. 62.

Storey J and Quintas P (2001) Knowledge management and HRM. In Human Resource Management: a Critical Text, 2nd edn. (Storey J (ed.)). Thomson Learning, London, UK, pp. 339-363.

Strauss A and Corbin J (1998) Basic of Qualitative Research: Techniques and Procedures for Developing Grounded Theory. Sage, Thousand Oaks, CA, USA.

Streubert HJ and Carpenter DR (1999) Qualitative Research in Nursing: Advancing the Humanistic Imperative. Lippincott, Philadelphia, PA, USA.

Studer R, Decker S, Fensel D and Staab S (2000) Situation and perspective of knowledge engineering. In Knowledge Engineering and Agent Technology (Cuenca J, Demazeau Y, Garcia Serrano A and Treur J (eds)). IOS Press, Amsterdam, the Netherlands, pp. 237-252.

Suresh S (2006) Knowledge Capture in Small and Medium Enterprises in the UK Construction Industry. $\mathrm{PhD}$ thesis, Glasgow Caledonian University, Glasgow, UK.

Suresh S, Gameson R and Chinyio E (2008) The role of knowledge management in reducing the cost of poor quality in the construction industry. Proceedings of Cobra 2007 RICS Foundation, Dublin, Ireland.

Taguchi G (1993) Taguchi on Robust Technology Development: Bringing Quality Engineering Upstream. The American Society of Mechanical Engineers, New York, NY, USA.

Tashakkori A and Teddlie C (2010) Sage Handbook of Mixed Methods in Social and Behavioral Research. Sage, Thousand Oaks, CA, USA.

Ten Have S, Have W, Stevens F and Elst M (2003) Key Management Models. Pearson Education Limited, London, UK.

Tiwana A (2002) The Knowledge Management Toolkit: Orchestrating IT, Strategy and Knowledge Platform, 2th edn. Prentice Hall, Upper Saddle River, NJ, USA.

Van der Spek R and Spijkervet A (1997) Knowledge management: dealing intelligently with knowledge. In Knowledge Management and Its Integrative Elements (Liebowitz J and Wilcox LC (eds)). CRC Press, Boca Raton, FL, USA, pp. 31-59.

Vorbeck J and Finke I (2001) Motivation and competence for knowledge management. In Knowledge Management: Best Practices in Europe (Mertins K, Heisig P and Vorbeck J (eds)). Springer, New York, NY, USA, pp. 37-56.

Wiig K (1997) Integrating intellectual capital and knowledge management. Long Range Planning 30(3): 399-405.

Wunram M (1999) Development of a Methodology and Mapping Mechanism for Assessing and Improving the Product Development Practice of Small and Medium Enterprises towards Concurrent Engineering. Research Unit Design and CAD, Faculty of Production Engineering, University of Bremen, Bremen, Germany.

Zin INM and Egbu C (2011) The significance of knowledge sharing approaches in Malaysian construction organisations. In Proceedings of 27th Annual ARCOM Conference, Association of Researchers in Construction Management, Bristol, UK (Egbu C and Lou ECW (eds)). Association of Researchers in Construction Management, London, UK, pp. 525-534. 